
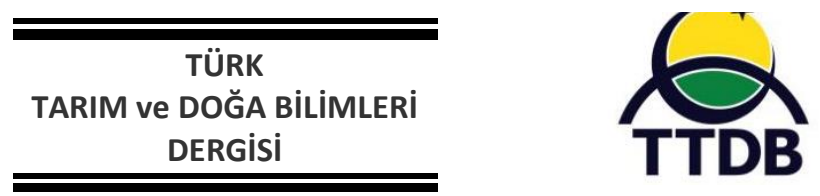

www.dergipark.gov.tr/turkjans

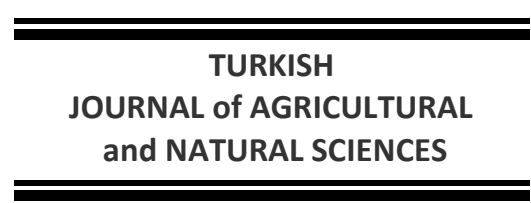

Araştırma Makalesi

\title{
Tortum Gölü Zooplakton Faunasının Mevsimsel Değişimi Araştırılması ${ }^{*}$
}

\author{
Muhammet ARDAHANLI, Özden FAKIOĞLU* \\ Atatürk Üniversitesi, Su Ürünleri Fakültesi, Temel Bilimler Bölümü, 25240, Erzurum, Türkiye \\ *Sorumlu yazar: ozden.fakioglu@atauni.edu.tr
}

Geliş Tarihi: 10.01.2020 Düzeltme Geliş Tarihi: 28.05.2020 Kabul Tarihi: 28.05.2020

\begin{abstract}
$\overline{\text { Öz }}$
Bu çalışma Tortum Gölü'nde zooplankton faunasının belirlenmesi ve mevsimsel değişimlerini incelemek amacıyla yürütülmüştür. Su ve zooplankton örnekleri Şubat 2017-Ocak 2018 tarihleri arasında ayda bir kez göl üzerinde seçilen 3 istasyondan alınmıştır. Gölün ortalama su sıcaklığı $9.74 \pm 2.89^{\circ} \mathrm{C}$, çözünmüş oksijen $6.81 \pm 1.00 \mathrm{mg} \mathrm{I}-1, \mathrm{pH} 8.48 \pm 0.12$ ve elektrik iletkenliği $0.289 \pm 0.03 \mathrm{mS} / \mathrm{cm}$ olarak ölçülmüştür. Tortum Gölü'nde, Rotifera (5) ve Artropoda (8) şubesine ait toplam 13 tür teşhis edilmiştir. Bu çalışmada, Kopepoda alt sınıfından Acartia (Acartiura) clausi \%17 ile en fazla teşhis edilen tür olmuştur. Bu türü göldeki \%15 ile zooplankton türlerine ait nauplius ve \%13 ile Eudiaptomus gracilis takip etmiştir. Teşhis edilen türler içerisinde Daphnia longispina ve Cyclops kolensis \%11, Daphnia cucullata ve Brachionus sp. \%8, Keratella cochlearis \%6, Daphnia pulex \%5, Filinia longiseta ve Polyarthra sp. \%2, Asplanchna herricki ve Daphnia magna \%1 oranında tespit edilmiştir. Tortum Gölü'nün baskın zooplankton türleri Eudiaptomus gracilis ve Acartia (Acartiura) clausi iken Asplanchna herricki ve Polyarthra sp. en az sıklıkla rastlanılan türler olarak saptanmıştır. Shannon-Wiener Çeşitlilik Indeksi değeri ortalama olarak hesaplanmış ve $\left(0.17 \mathrm{H}^{\prime}\right)$ istasyona bağlı değişimi 3ist $>2$ ist $>1$.ist olarak sıralanmıştır. Margalef Çeşitlilik Indeksine göre en fazla çeşitlilik ağustos ayında 2. istasyonda, en az çeşitlilik ise Şubat ayında 1. ve 3. istasyonda tespit edilmiştir. Sonuç olarak bu çalışma Erzurum il sınırları içerisinde yapılan ilk zooplankton çalışması olmuştur. Bu çalışmanın, bölgedeki sucul alanların biyolojik özelliklerinin araştırıımasını önemli katkılar sağlayacağı düşünülmektedir.
\end{abstract}

Anahtar Kelimeler: Biyoçeşitlilik, Topluluk, Zooplankton, Tortum Gölü

\section{Seasonal Change Of Zooplankton Fauna In Tortum Lake}

\begin{abstract}
This study was carry out to determinate of zooplankton fauna and seasonal change. Water and zooplankton samples were taken from 3 stations between February 2017- Januvery 2018 in Tortum Lake. The mean water temperature $9.74 \pm 2.89^{\circ} \mathrm{C}$, the mean dissolved oxygen $6,81 \pm 1,00 \mathrm{mg} \mathrm{L}^{-1}$, the mean $\mathrm{pH}$ $8.48 \pm 0.12$ and the mean electrical conductivity $0.289 \pm 0.03 \mathrm{mS} \mathrm{cm}^{-1}$ was measured in the lake. A total of 13 species belonging to Rotifera (5) and Artropoda (8) were identified in Tortum Lake. In this study, Acartia (Acartiura) clause of sub class Copepoda was the most identified species with $17 \%$. Nauplius with $15 \%$ and Eudiaptomus gracilis with $13 \%$ were followed this species. In this zooplankton community were detected Daphnia longispina and Cyclops kolensis 11\%, Daphnia cucullata and Brachionus sp. 8\%, Keratella cochlearis 6\%, Daphnia pulex 5\%, Filinia longiseta and Polyarthra sp. 2\%, Asplanchna herricki and Daphnia magna 1\%. Eudiaptomus gracilis and Acartia (Acartiura) clausi were the most dominant species, while Asplanchna herricki and Polyarthra sp. were the least frequency species. Shannon-Wiener Diversity Index values was calculated $0.17 \mathrm{H}^{\prime}$ and it's depending on the stations were listed as 3ist> 2ist> 1.ist. According to the Margalef Diversity Index, the highest diversity was detected in the second station in August and the least diversity in the first and third stations in February. As a result, this study was the first zooplankton study in Erzurum. This study is thought to encourage the investigation of biological researches of aquatic system in the region.
\end{abstract}

Keywords: Biodiversity, Community, Zooplankton, Tortum Lake 


\section{Giriş}

Zooplankton ve fitoplankton toplulukları ile birlikte su ürünlerini oluşturan organizmalara doğrudan veya dolaylı besin sağlamak suretiyle doğal su ürünlerinin gelişmeleri üzerinde önemli etkilere sahiptirler. Tatlı sularda ötrofikasyon çalışmalarında, suda meydana gelen değişimlerin ilk olarak fitoplankton ve zooplanktonik organizmalar üzerinde olduğunun ve bu organizmaların tür kompozisyonunu değiştirdiğinin ortaya koyulması göllerde zooplankton çalışmalarının yapılmasını daha önemli hale getirmiştir (İpek, 2015).

Ülkemizde zooplankton organizmaları üzerine yapılan çalışmalar çok eski tarihlere dayanmaktadır. Zooplankton üzerine yapılan ilk çalışma, Daday (1903)'ın Apolyont ve İznik Gölleri'nde yapmış olduğu çalışmadır. Bu çalışmayı 1905 yılında Vavra ve 1907 yılında Zederbauer and Brehm'in Sarı Göl'ün zooplanktonu üzerine yapmış oldukları taksonomik çalışmalar takip etmiştir (İpek, 2015). Ustaoğlu (2015) Ülkemizdeki zooplankton çalışmalarını raporlamış ve zooplankton topluluklarına ilişkin 2015 yılına kadar yaklaşık 120 çalışmada 417 rotifer, 103 kladoser ve 141 kopepod türlerinin teşhis edildiğini bildirmiştir.

Tortum Gölü derin heyelan set gölüdür. Gölün batı yakası boyunca uzanan ErzurumArtvin karayolu, kayalar yontularak açılmıştır (Altuner, 1982). Tortum Gölü'nün etrafı dağlarla çevrilidir. Tortum Gölü'nde fitoplankton ve bentik alg yapısı 1979-1981, 2002-2003, 2013-
2014 ve 2017-2018 dönemleri arasında incelenmiştir. Bu çalışmalarda gölün fizikokimyasal parametrelerinin yanı sıra fitoplankton topluluklarının tür kompozisyonları ve mevsimsel değişimleri araştırılmıştır. Çalışmalarda fitoplankton biyo çeşitliliğinin çok düşük olduğu bildirilmiştir. Gölün 1979-1981 yılında oligotrofik olarak tespit edilmişlerdir. Ancak 35 yılda gölün trofik düzeyinin mesotrofik seviyeye ulaştığı belirtilmiştir (Altuner, 1982; Kıvrak, 2006; Fakıoglu ve ark., 2018a; Fakıoğlu ve ark., 2018b). Tortum Gölü'nde zooplankton topluluklarının çeşitliliği ve mevsimsel değişimine dair bir çalışma daha önce yapılmamıştır.

$\mathrm{Bu}$ çalışmada, Tortum Gölü'ndeki zooplankton topluluklarının tür kompozisyonunu ve mevsimsel değişimlerini araştırmak amacıyla yürütülmesi planlanmıştır.

\section{Materyal ve Yöntem \\ Araştırma sahası}

Tortum Gölü, Erzurum'un kuzeydoğusunda yer alan doğal bir heyelan-set gölüdür. Göl $40^{\circ} 35^{\prime}-40^{\circ} 39^{\prime} \mathrm{K}$ ve $41^{\circ} 38^{\prime} \mathrm{D}$ enlemlerinde olup Erzurum ili'ne uzaklığı yaklaşık 95 km'dir. Göl ortalama 8 km uzunluk ve yaklaşık olarak $0.7 \mathrm{~km}$ genişliğe sahiptir. Tortum Gölü derin heyelan set gölüdür ve ortalama derinliği $100 \mathrm{~m}$ olarak bildirilmiştir (Fakıoğlu ve ark., 2018b). Tortum Çayı, gölü besleyen en önemli kaynaktır (Kıvrak, 2006; Kıvrak ve Gürbüz, 2010). Tortum Gölü ve istasyonlara ait bilgiler şekil 1'de verilmiştir.

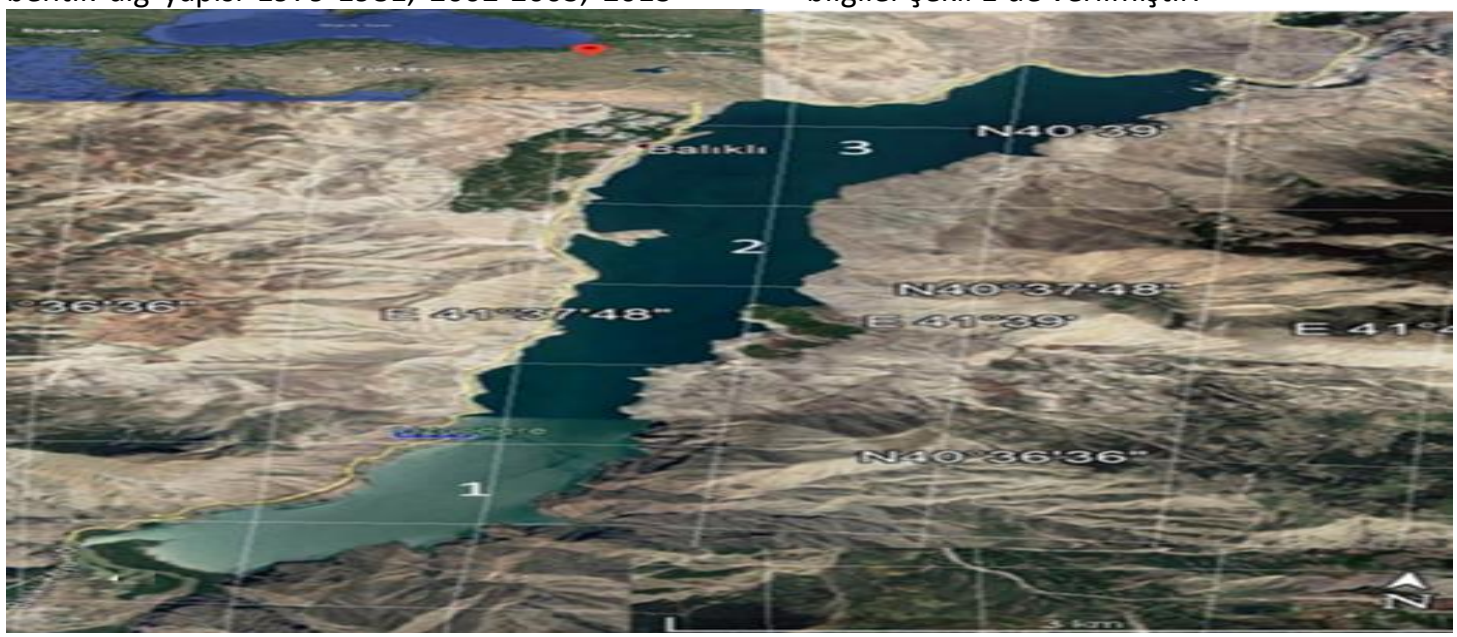

Şekil 1. Tortum Gölü haritası ve istasyonlar

\section{Saha çalışması ve örneklerin alınması}

Tortum Gölü (Erzurum)'nde Şubat 2017Ocak 2018 tarihleri arasında ayda bir kez 3 istasyondan su ve zooplankton örneği alınmıştır.
Zooplankton örneklerinin alınmasında $50 \mu$ göz açıklığında ağa sahip plankton kepçesi ve kantitatif zooplankton ve su örnekleri almak için ise Ruttner su örnek alma aleti kullanılmıştır. 
Örnekler epilimyon ve metalimyon tabakalarından alınan suların karıştırılması ile 2000 ml'lik polietilen örnek alma kaplarıyla, zooplankton kepçesi ile çekilen örnekler ise \%4 formaldehit ilavesi ile muhafaza edilerek laboratuvara getirilmiştir. Arazi çalışmaları sırasında su sıcaklığı, çözünmüş oksijen, pH ve elektiriksel iletkenlik (EC) yerinde YSI marka multiparametre aleti ile yerinde ölçülmüştür.

\section{Zooplankton teşhisi ve sayımı}

Laboratuvara getirilen zooplankton türlerinin teşhisleri ve fotoğraf çekimleri Zeiss marka binoküler mikroskop ve sayımları ise Zeiss marka stereo mikroskop altında yapılmıştır. Örneklerin tür teşhisinde, Thorp ve Covich (2001) kaynağından yararlanılmıştır.

Zooplankton sayımında 1000 ml'lik kaplardan homojen olacak şekilde $40 \mathrm{ml}$ 'lik örnek sayım küvetine dökülerek sayım işlemleri yapılmıştır. Her sayım 3'er kez tekrarlı olarak yapılmıştır. $1 \mathrm{~m}^{3}$ sudaki zooplankton sayısı aşağıdaki formüle göre hesaplanmıştır (Akbay 1982; Cirik ve Gökpınar 1999):

$1 \mathrm{~m}^{3 \prime}$ deki birey sayısı (zooplankton $/ \mathrm{m}^{3}$ ) $=1$ $\mathrm{cc}^{\prime}$ deki birey sayısı $/ \pi \times \mathrm{r}^{2} \times \mathrm{h} \times 10^{6}$

$r=$ Kepçe yarıçapı $(\mathrm{cm})$

$\mathrm{h}=$ Çekme derinliği $(\mathrm{cm})$

\section{Sıklık (frekans)}

Belli bir sahada birden fazla örnekleme yapıldığında bir türe ait bireylere her zaman rastlama olanağı yoktur. Çalışmada rastlanan örnekleme sayısının tüm örnekleme sayısına oranının yüzdesi, o türün sıklık derecesini gösterir (Kocataş, 2010).

Sıklık $(\mathrm{F})=\left(\mathrm{N}_{\mathrm{a}} / \mathrm{N}_{\mathrm{n}}\right) \times 100$ (F: Frekans (Sıklık), $\mathrm{N}_{\mathrm{a}}$ : A türünü içeren örnekleme sayısı

$\mathrm{N}_{\mathrm{n}}$ : Tüm örnekleme sayısı)

\section{Baskınlık (dominans)}

Dominans, organizmanın habitatı üzerindeki etkisi olarak tanımlanır. Bir türe ait bireylerin, tüm türlere ait toplam birey sayısı arasındaki oranın yüzde ifadesidir (Kreps, 1989). Dominans $=(N A / N n) \times 100$ (NA: A türüne ait birey sayısı, $\mathrm{Nn}$ : Tüm bireylere ait birey sayısı)

\section{Shannon-Wiener çeşitlilik indeksi $\left(H^{\prime}\right)$;}

$$
\mathrm{H}^{\prime}=-\sum_{\mathrm{i}=1}^{\mathrm{S}} \mathrm{p}_{\mathrm{i}} \log _{\mathrm{e}} \mathrm{p}_{\mathrm{i}}
$$

pi: ni/n [(H': İndeks değerini, s: Tür sayısını ve pi: i. türe ait birey sayısının (ni) toplam birey sayısına (n) oranını göstermektedir (Krebs, 1989;
Kwak ve Peterson, 2007; James ve Aderaje, 2010)].

\section{Margalef çeşitlilik indeksi $\left(D_{m g}\right)$}

$\mathrm{D}_{\mathrm{mg}}=\mathrm{S}-1 / \log \mathrm{N}$

[(Dmg: İndeks değerini, S: Toplam tür sayısını ve $\mathrm{N}$ : Örnekte yer alan toplam birey sayısını göstermektedir (James ve Aderaje, 2010)].

\section{Istatistik analizler}

Tortum Gölü'ne yürütülen bu çalışmada seçilen 3 istasyonda aylara ve istasyonlara bağlı su sıcaklığı, çözünmüş oksijen, pH, elektrik iletkenliği değerlerinin istasyon ve mevsime bağı değişimi ile zooplankton topluluklarının frekans değeri IBM SPSS 20 programında farklılık faktöriyel düzende Varyans Analizi (ANOVA) kullanarak analiz edilmiştir. Gruplar arası farklılığın önem düzeyinin belirlenmesinde DUNCAN testi kullanılmıştır.

\section{Araştırma Bulguları ve Tartışma}

Tortum Gölü'nün bulunduğu havzadan dolayı mikro-klima özelliği göstermektedir (Duman, 2009). Bu nedenle göl hem derin hem de kış aylarında gölün üzeri buzla kaplı değildir. Tortum Gölü'ne ait su sıcaklığı kış aylarında ortalama $6^{\circ} \mathrm{C}$ ölçülmüştür. Bu araştırmada göl yüzeyinde kış aylarında donma gözlenmemiştir. Su sıcaklığı değeri aylara ve istasyonlara bağlı değişimi istatistiki olarak önemli bulunmuştur $(p<0.05)$. Su sıcaklığı değeri en düşük Şubat ayında 2. istasyonda $\left(4.41 \pm 0.09^{\circ} \mathrm{C}\right)$, en yüksek su sıcaklığı değeri ise Ağustos ayında 1. istasyonda $\left(15.4 \pm 8.08^{\circ} \mathrm{C}\right.$ ) tespit edilmiştir (Çizelge 1 ).

Araştırma boyunca göldeki çözünmüş oksijen değeri aylara ve istasyonlara bağlı değişimi istatistiki olarak önemli bulunmuştur $(p<0.05)$. Çözünmüş oksijen değerinin istasyonlara ve aylara bağı değişiminde, en düşük değeri Eylül ayında 1 . istasyonda (5.76 $\pm 0.37 \mathrm{mg} \mathrm{l-1)}$ ve en yüksek değeri Nisan ayında 1. İstasyonda $(9.64 \pm 0.29 \mathrm{mg} \mathrm{l}$ l-1) ölçülmüştür (Çizelge 1). Ortalama çözünmüş oksijen değeri $6.81 \pm 1.00 \mathrm{mg} \mathrm{I-1}$ olarak tespit edilmiştir. Türk Çevre Mevzuatı Kıta İçi Su Kaynakları Sınıflandırmasına göre II. sınıf kaliteli sular sınıfına girmektedir (Anonim, 2012).

Tortum Gölü'nde yürütülen bu araştırmada $\mathrm{pH}$ ve elektrik iletkenliği değerleri istasyonlara ve aylara bağlı değişimi istatistiki olarak önemli bulunmuştur $(p<0.05)$. $\mathrm{pH}$ değeri en düşük Şubat 1 . istasyon ve Nisan 3. istasyonda sırasıyla $8.30 \pm 0.07$ ve $8.30 \pm 0.08$ 
olarak tespit edilmiştir. En yüksek $\mathrm{pH}$ değeri ise $8.71 \pm 0.20$ olarak Aralık 1 . istasyonda saptanmıştır. Elektrik iletkenliği değeri ise 0.26 $\mathrm{mS} / \mathrm{cm}$ ile $0.32 \mathrm{mS} / \mathrm{cm}$ arasında değişim göstermiştir. En yüksek değeri geç sonbahar döneminde ölçülmüştür (Çizelge 1). Gölün ortalama $\mathrm{pH}$ değeri $8.48 \pm 0.12$ olarak ölçülmüştür. Tortum Gölü ortalama pH değerine göre Kıta İçi Su Kaynakları Sınıflandırılmasına
(Anonim, 2012) göre I. sınıf kalite sular sınıfında yer almaktadır. Bu çalışmada, elektrik iletkenliği ortalama $0.289 \pm 0.03 \mathrm{mS} / \mathrm{cm}$ olarak saptanmıştır. Gölde 2006 yılında yürütülmüş olan çalışmada elektrik iletkenliği değeri ortalama $308 \mu \mathrm{S} / \mathrm{cm}$ bulunmuştur (Kıvrak, 2006). Dışarıya akıntısı olan doğal göllerde 100$1000 \mu \mathrm{S} / \mathrm{cm}$ aralığında bir iletkenlik değerine sahiptir (Öztürk, 2014).

Çizelge 1. Tortum Gölü fiziko-kimyasal su kalite parametrelerinin aylara ve istasyonlara bağlı değişimi (ORT $\pm S D, n=4)$

\begin{tabular}{|c|c|c|c|c|c|}
\hline Aylar & İstasyon & Su Sıcaklığı (으) & $\begin{array}{l}\text { Çözünmüş } \\
\text { Oksijen (mg l-1) }\end{array}$ & $\mathrm{pH}$ & $\mathrm{EC}(\mathrm{mS} / \mathrm{cm})$ \\
\hline \multirow[t]{3}{*}{ Şubat } & 1 & $4.16 \pm 0.05^{A g^{*}}$ & $8.05 \pm 0.87^{\mathrm{Aa}}$ & $8.30 \pm 0.07^{\mathrm{Ce}}$ & $0.26 \pm 0.00^{\mathrm{Ad}}$ \\
\hline & 2 & $4.41 \pm 0.09 \mathrm{Ag}$ & $7.69 \pm 0.10^{\mathrm{Bb}}$ & $8.38 \pm 0.04^{\mathrm{Af}}$ & $0.26 \pm 0.00^{\mathrm{Ad}}$ \\
\hline & 3 & $4.45 \pm 0.13 \mathrm{Ah}$ & $7.98 \pm 0.28^{\mathrm{Bb}}$ & $8.36 \pm 0.02^{\mathrm{Be}}$ & $0.26 \pm 0.00^{\mathrm{Ad}}$ \\
\hline \multirow[t]{3}{*}{ Mart } & 1 & $6.02 \pm 0.58 \mathrm{Af}$ & $6.63 \pm 0.56 \mathrm{Ac}$ & $8.34 \pm 0.08^{\mathrm{Be}}$ & $0.27 \pm 0.00^{A c}$ \\
\hline & 2 & $6.50 \pm 0.55^{\mathrm{Ae}}$ & $6.46 \pm 0.26 \mathrm{Ac}$ & $8.42 \pm 0.03 \mathrm{Ae}$ & $0.27 \pm 0.00^{\mathrm{Ac}}$ \\
\hline & 3 & $5.73 \pm 0.39^{\mathrm{Bg}}$ & $6.62 \pm 0.06 \mathrm{Ac}$ & $8.42 \pm 0.01^{\mathrm{Ad}}$ & $0.27 \pm 0.00^{\mathrm{Ac}}$ \\
\hline \multirow[t]{3}{*}{ Nisan } & 1 & $7.57 \pm 0.90^{\mathrm{Ae}}$ & $9.64 \pm 0.29 \mathrm{Aa}$ & $8.56 \pm 0.07^{\mathrm{Ab}}$ & $0.28 \pm 0.01^{\mathrm{Ab}}$ \\
\hline & 2 & $6.97 \pm 1.20^{\mathrm{Be}}$ & $8.26 \pm 0.66$ Ва & $8.51 \pm 0.07^{\mathrm{Bd}}$ & $0.28 \pm 0.01^{\mathrm{Ab}}$ \\
\hline & 3 & $6.87 \pm 1.09^{\mathrm{Bf}}$ & $8.24 \pm 0.55^{\mathrm{Ba}}$ & $8.30 \pm 0.08^{\mathrm{Ce}}$ & $0.28 \pm 0.01 \mathrm{Ac}$ \\
\hline \multirow[t]{3}{*}{ Mayıs } & 1 & $10.5 \pm 2.91^{\mathrm{Ad}}$ & $7.23 \pm 0.54^{\mathrm{Ab}}$ & $8.47 \pm 0.05^{\mathrm{Ac}}$ & $0.27 \pm 0.02^{\mathrm{BC}}$ \\
\hline & 2 & $10.5 \pm 2.46^{\mathrm{Ad}}$ & $7.25 \pm 0.13^{\mathrm{Ab}}$ & $8.37 \pm 0.07^{\mathrm{Bf}}$ & $0.28 \pm 0.01^{\mathrm{Ab}}$ \\
\hline & 3 & $9.95 \pm 2.70^{\mathrm{Bd}}$ & $7.09 \pm 0.43^{\mathrm{Ab}}$ & $8.35 \pm 0.02 \mathrm{Ce}$ & $0.28 \pm 0.01^{A c}$ \\
\hline \multirow[t]{3}{*}{ Haziran } & 1 & $10.9 \pm 2.92^{\mathrm{Ad}}$ & $7.32 \pm 0.65^{\mathrm{Ab}}$ & $8.60 \pm 0.14^{\mathrm{Aa}}$ & $0.25 \pm 0.03^{\mathrm{Be}}$ \\
\hline & 2 & $10.5 \pm 2.99 \mathrm{Ad}$ & $6.73 \pm 0.42^{\mathrm{Bc}}$ & $8.46 \pm 0.01^{\mathrm{cd}}$ & $0.26 \pm 0.02^{\mathrm{Ad}}$ \\
\hline & 3 & $10.4 \pm 3.00^{\mathrm{Ad}}$ & $6.94 \pm 0.56^{\mathrm{Bc}}$ & $8.51 \pm 0.05^{\mathrm{Bd}}$ & $0.26 \pm 0.02^{\mathrm{Ad}}$ \\
\hline \multirow[t]{3}{*}{ Temmuz } & 1 & $14.9 \pm 6.40^{\mathrm{Ab}}$ & $7.39 \pm 1.33 \mathrm{Ab}$ & $8.54 \pm 0.14 \mathrm{Cb}$ & $0.30 \pm 0.04 \mathrm{Ba}$ \\
\hline & 2 & $14.6 \pm 6.20^{\mathrm{Ab}}$ & $6.90 \pm 1.02^{\mathrm{Bc}}$ & $8.60 \pm 0.14 \mathrm{Aa}$ & $0.31 \pm 0.01^{\mathrm{Aa}}$ \\
\hline & 3 & $14.4 \pm 6.01 \mathrm{Ab}$ & $7.00 \pm 0.35^{\mathrm{Ab}}$ & $8.57 \pm 0.10^{\mathrm{Ba}}$ & $0.30 \pm 0.01^{\mathrm{Bb}}$ \\
\hline \multirow[t]{3}{*}{ Ağustos } & 1 & $15.4 \pm 8.08^{\mathrm{Aa}}$ & $6.81 \pm 1.17^{\mathrm{Ac}}$ & $8.43 \pm 0.14^{\mathrm{Cd}}$ & $0.32 \pm 0.03^{\mathrm{Aa}}$ \\
\hline & 2 & $15.1 \pm 7.55^{\mathrm{Aa}}$ & $6.89 \pm 1.66 \mathrm{Ac}$ & $8.50 \pm 0.07^{\mathrm{Ab}}$ & $0.31 \pm 0.02^{\text {Ва }}$ \\
\hline & 3 & $15.2 \pm 7.79 \mathrm{Aa}$ & $6.38 \pm 1.42^{\mathrm{Ac}}$ & $8.44 \pm 0.12^{\mathrm{Bd}}$ & $0.31 \pm 0.02 \mathrm{Ba}$ \\
\hline \multirow[t]{3}{*}{ Eylül } & 1 & $14.2 \pm 5.98^{\mathrm{Ab}}$ & $5.76 \pm 0.37^{\mathrm{Bd}}$ & $8.57 \pm 0.14^{\mathrm{Bd}}$ & $0.32 \pm 0.02^{\mathrm{Aa}}$ \\
\hline & 2 & $14.2 \pm 6.14^{\mathrm{Ab}}$ & $6.31 \pm 0.52^{\mathrm{Ac}}$ & $8.52 \pm 0.08^{\mathrm{Ab}}$ & $0.31 \pm 0.02 \mathrm{Ba}$ \\
\hline & 3 & $14.2 \pm 6.16^{\mathrm{Ab}}$ & $6.37 \pm 0.84 \mathrm{Ac}$ & $8.52 \pm 0.07^{\mathrm{Aa}}$ & $0.32 \pm 0.02^{\mathrm{Aa}}$ \\
\hline \multirow[t]{3}{*}{ Ekim } & 1 & $11.2 \pm 4.06 \mathrm{Ac}$ & $5.89 \pm 0.44^{\mathrm{Bd}}$ & $8.55 \pm 0.11^{\mathrm{Ab}}$ & $0.30 \pm 0.02^{\mathrm{Aa}}$ \\
\hline & 2 & $11.5 \pm 4.03 \mathrm{Ac}$ & $6.00 \pm 0.20^{\mathrm{Ad}}$ & $8.48 \pm 0.05^{c c}$ & $0.30 \pm 0.02^{\mathrm{Aa}}$ \\
\hline & 3 & $11.4 \pm 4.09 \mathrm{Ac}$ & $5.95 \pm 0.28^{\mathrm{Bd}}$ & $8.51 \pm 0.10^{\mathrm{Ba}}$ & $0.30 \pm 0.02^{\mathrm{Ab}}$ \\
\hline \multirow[t]{3}{*}{ Kasım } & 1 & $10.1 \pm 2.80^{\mathrm{Ad}}$ & $5.77 \pm 0.64 \mathrm{Bd}$ & $8.59 \pm 0.14 \mathrm{Aa}$ & $0.29 \pm 0.02 \mathrm{Bb}$ \\
\hline & 2 & $10.1 \pm 2.81 \mathrm{Ad}$ & $5.94 \pm 0.53 \mathrm{Bd}$ & $8.49 \pm 0.08 \mathrm{Aa}$ & $0.29 \pm 0.01^{\mathrm{Bb}}$ \\
\hline & 3 & $10.2 \pm 2.77^{\mathrm{Ad}}$ & $6.13 \pm 0.13 \mathrm{Ac}$ & $8.48 \pm 0.11^{\mathrm{cb}}$ & $0.30 \pm 0.02^{\mathrm{Ab}}$ \\
\hline \multirow[t]{3}{*}{ Aralık } & 1 & $6.65 \pm 0.36 \mathrm{Af}$ & $6.14 \pm 0.85^{\mathrm{Ac}}$ & $8.71 \pm 0.20^{\mathrm{Aa}}$ & $0.27 \pm 0.00^{A c}$ \\
\hline & 2 & $6.78 \pm 0.41^{\mathrm{Ae}}$ & $6.39 \pm 0.79 \mathrm{Ac}$ & $8.48 \pm 0.07^{B C}$ & $0.27 \pm 0.00^{A c}$ \\
\hline & 3 & $6.68 \pm 0.37 \mathrm{Ac}$ & $6.35 \pm 0.56 \mathrm{Ac}$ & $8.43 \pm 0.03 \mathrm{~cd}$ & $0.27 \pm 0.00^{A c}$ \\
\hline \multirow[t]{3}{*}{ Ocak } & 1 & $4.83 \pm 0.05^{\mathrm{Ch}}$ & $6.67 \pm 0.51 \mathrm{Ac}$ & $8.52 \pm 0.06^{\mathrm{Ab}}$ & $0.27 \pm 0.00^{A c}$ \\
\hline & 2 & $5.80 \pm 0.00^{\mathrm{Be}}$ & $6.57 \pm 0.38 \mathrm{Ac}$ & $8.46 \pm 0.01^{\mathrm{Bd}}$ & $0.27 \pm 0.00^{A c}$ \\
\hline & 3 & $7.78 \pm 0.04 \mathrm{Ae}$ & $6.25 \pm 0.46 \mathrm{Ac}$ & $8.46 \pm 0.02 \mathrm{Bc}$ & $0.27 \pm 0.00 \mathrm{Ac}$ \\
\hline
\end{tabular}

*A,B,C: Büyük harfler her bir parametre için aynı aydaki istasyonlar arasındaki farkı göstermektedir ve aynı sütunda farklı büyük harf taşıyan istasyonlar arasındaki fark istatistiki olarak önemlidir $(p<0,05)$.

a, b, c, d..: Küçük harfler her bir parametre için aynı istasyondaki aylar arasındaki farkı göstermektedir ve aynı sütunda farklı küçük harf taşıyan aylar arasındaki fark istatistiki olarak önemlidir $(p<0,05)$.

Tortum Gölü'nde yürütülen çalışmada, Rotifera (Asplanchna herricki, Brachionus sp.,
Filinia longiseta, Keratella cochlearis ve Polyarthra sp.) ve Artropoda (Daphnia 
longispina, Daphnia cucullata, Daphnia magna, Daphnia pulex, Cyclops kolensis, Eudiaptomus gracilis ve Acartia (Acartiura) clausi) şubesine ait toplam 13 tür teşhis edilmiştir (Çizelge 2). Demirdöven Baraj Gölü'nde (Erzurum) yapılan bir çalışmada, Kopepoda'dan Cyclops abyssorum, Cyclops vicinus, Eudiaptomus vulgaris ve Metacyclops stammeri, Kladosera'dan Daphnia cucullata, Rotifera'dan Asplanchna priodonta, Kelicottia longispina ve Keratella cochlearis türlerini yaz aylarında saptamışlardır (Dorak ve ark., 2019).

Çizelge 2. Tortum Gölü'nün zooplankton tür listesi

\begin{tabular}{l} 
Şube :Arthropoda \\
Alt Şube : Crustacea \\
Sınıf : Branchiopoda \\
Takım : Kladosera \\
Aile : Daphniidae \\
Cins : Daphnia \\
Tür : Daphnia cucullata Sars, 1862 \\
Tür: Daphnia longispina O.F.Müller, 1776 \\
Tür: Daphnia magna Straus, 1820 \\
Tür: Daphnia pulex Leydig, 1860 \\
Alt Sınıf : Kopepoda \\
Takım : Calanoida \\
Aile : Acartidae \\
Tür : Acartia (Acartiura) clausi Giesbrecht, 1889 \\
Aile : Diaptominae \\
Tür : Eudiaptomus gracilis G.O. Sars, 1863 \\
Tür : Nauplius \\
Takım : Collothecaceae \\
Aile : Collothecidae \\
Cins : Cyclops O.F. Müller, 1785 \\
Tür : Cyclops kolensis Lilljeborg, 1901 \\
\hline
\end{tabular}

Şube : Rotifera Cuvier, 1817

Takım : Monogononta

Aile : Brachionidae

Cins : Brachionus

Tür : Brachionus sp.

Cins : Keratella

Tür : Keratella cochlearis Gosse, 1851

Aile : Asplanchnidae

Cins : Asplanchna

Tür : Asplanchna herricki De Guerne, 1888

Aile : Filiniidae

Cins : Filinia

Tür : Filinia longiseta Ehrenberg, 1834

Aile : Synchaetidae

Cins : Polyarthra

Tür : Polyarthra sp.
Çalışma periyodu boyunca örneklenen zooplankton türlerinin $\% 19$ 'u Rotifera şubesinden ve \%81'i Arthropada şubesinden ki bu şubenin de \%56'sını Kopepoda ve \%25'ini Kladosera takımı oluşturmuştur. Ülkemizde yapılan çalışmalarda daha çok Rotifer şubesine ait türler teşhis edilirken (Altındağ ve Yiğit, 2004; Saler, 2004; Türkmen ve ark., 2006; Özdemir ve ark., 2009; Ustaoğlu ve ark., 2010; Saler ve Alış, 2014; Velioğlu ve Kırkağaç, 2017), bu çalışmada, Artropoda şubesine ait bireylerin sayısının daha fazla olduğu gözlemlenmiştir. Gölde teşhis edilen türleri dağılımına baktığımızda Acartia (Acartiura) clausi (\%17) en fazla teşhis edilen tür olmuştur. Bu türü Nauplius (\%15) ve Eudiaptomus gracilis (\%13) takip etmiştir. Teşhis edilen türler içerisinde Daphnia longispina ve Cyclops kolensis \%11, Daphnia cucullata ve Brachionus sp. \%8, Keratella cochlearis \%6, Daphnia pulex \%5, Filinia longiseta ve Polyarthra sp. \%2, Asplanchna herricki ve Daphnia magna $\% 1$ oranında bulunmuştur (Şekil 2). Bunlardan Keratella cochlearis rotiferler içinde kozmopolit olarak sayılan bir türdür. Farklı ortam koşullarına adaptasyonu oldukça yüksektir. Bununla birlikte beş farklı tatlısu ekosisteminde mevsimsel zooplankton dağılımının incelediği çalışmada tür dağılımına en fazla etki eden etmenlerin elektrik iletkenliği ve çözünmüş oksijen miktarı olduğu ve bunları $\mathrm{pH}$ 'nın takip ettiği bildirilmiştir (Buyurgan, 2013). 


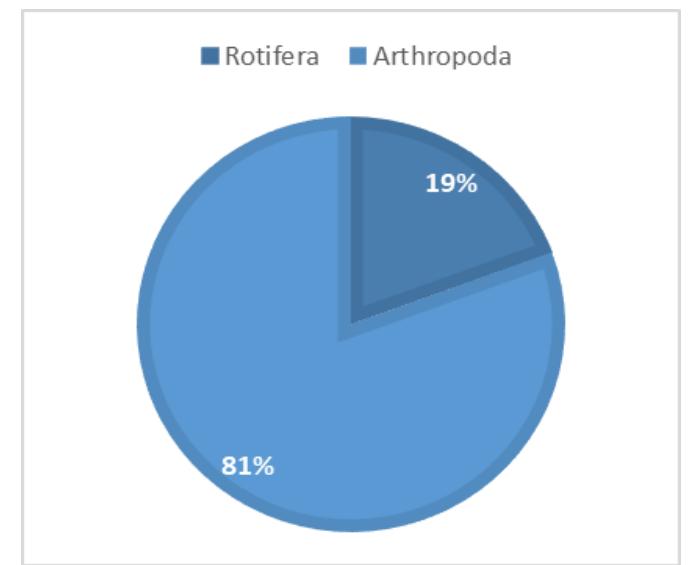

Şekil 2. Zooplankton türlerin sayısal dağılımı (\%)

$\mathrm{Bu}$ araştırmada Eudiaptomus gracilis ve Acartia (Acartiura) clausi türleri hemen hemen bütün aylarda sıklıkla görülmüştür. Eudiaptomus gracilis sadece Ocak ayında, Acartia (Acartiura) clausi ise Şubat ayın da tespit edilmemiştir. Nauplius ise Mart, Mayıs, Haziran ve Ekim aylarında sıklıkla görülmüştür. Cyclops kolensis Şubat, Eylül ve Aralık aylarında tespit edilmemiştir. Daphnia longispina Mayıs ve Aralık ayları hariç, Daphnia pulex nisan, Eylül ve Ekim ayları dışında sıklıkla saptanmıştır. Daphnia manga sadece Haziran ve Temmuz aylarında sıklıkla bulunmuştur. Daphnia cucullata Şubat,
Mart, Ağustos ve Aralık ayları dışında sıklıkla tespit edilmiştir (Çizelge 3). Ötrofik göllerin dominant türleri Brachionus, Keratella, Polyarthra ve Filinia cinsleridir (Güher, 2003; Kaya ve Altındağ, 2007). Yine ötrofik bir göl olan Mogan Gölü'nde yürütülen bir çalışmada zooplankton dağılımında pH'nın önemli derecede etkili olduğunu, alkali suları seven Keratella sp., Brachionus angularis, Brachionus calyciflorus ve Trichocerca sp. türlerine sıklıkla rastlanıldığını bildirmişlerdir (Velioğlu ve Kırkağaç, 2017).

Çizelge 3. Zooplankton türlerinin aylara göre sıklık (frekans) dağlımı (\%)

\begin{tabular}{|c|c|c|c|c|c|c|c|c|c|c|c|c|}
\hline Türler & Şubat & Mart & Nisan & Mayıs & Haziran & Temmuz & Ağustos & Eylül & Ekim & Kasım & Aralık & Ocak \\
\hline Artropoda & & & & & & & & & & & & \\
\hline D.cucullata & & & 23.07 & 23.07 & 18.75 & 17.64 & & 15.38 & 23.07 & 7.14 & & 12.5 \\
\hline D.longispina & 37.5 & 18.75 & 23.07 & & 18.75 & 17.64 & 25 & 23.07 & 23.07 & 21.42 & & 6.25 \\
\hline D.magna & & & & & 6.25 & 11.76 & & & & & & \\
\hline D.pulex & 25 & 12.5 & & 7.69 & 12.5 & 17.64 & 8.33 & & & 14.28 & 16.6 & 18.75 \\
\hline $\begin{array}{l}\text { Cyclops } \\
\text { kolensis }\end{array}$ & & 12.5 & 15.38 & 7.69 & 12.5 & 5.88 & 16.66 & & 7.69 & 14.28 & & 6.25 \\
\hline Nauplius & & 18.75 & & 23.07 & 12.5 & & & & 7.69 & & & \\
\hline $\begin{array}{l}\text { Eudiaptomus } \\
\text { gracilis }\end{array}$ & 35.5 & 18.75 & 23.07 & 23.07 & 6.25 & 5.88 & 25 & 23.07 & 23.07 & 21.42 & 16.6 & \\
\hline Acartia & & & & & & & & & & & & \\
\hline $\begin{array}{l}\text { (Acartiura) } \\
\text { clausi }\end{array}$ & & 12.5 & 15.38 & 7.69 & 12.5 & 17.64 & 16.66 & 23.07 & 7.69 & 14.28 & 50 & 12.5 \\
\hline Rotifera & & & & & & & & & & & & \\
\hline $\begin{array}{l}\text { Brachionus } \\
\text { sp. }\end{array}$ & & 6.25 & & & & 5.88 & 8.33 & 7.69 & 7.69 & 7.14 & & 12.5 \\
\hline K.cochlearis & & & & 7.69 & & & & & & & & 6.25 \\
\hline A.herricki & & & & & & & & & & & & 6.25 \\
\hline F.longiseta & & & & & & & & & & & 16.6 & 12.5 \\
\hline $\begin{array}{l}\text { Polyarthra } \\
\text { sp. }\end{array}$ & & & & & & & & & & & & 6.25 \\
\hline
\end{tabular}

Bu çalışmada ilkbahar aylarında Eudiaptomus gracilis ve D.cucullata baskın türler olarak bulunmuştur. Yaz aylarında D. longisipina ve Acartia (Acartiura) clausi. sonbahar aylarında 
daha çok kopepod türlerinin baskın türler olduğu belirlenmiştir. Kış aylarında ise en baskın türler Acartia (Acartiura) clausi ve Eudiaptomus gracilis olarak tespit edilmiştir (Şekil 3). Rotifera faunası. mevsimsel ve perennial tür olmak üzere ikiye ayrılırken. mevsimsel türler yaz ve kış formu olmak üzere ikiye ayrılırlar. Perennial türler ise yaz başında maksimum artış gösterirken yaz sonu ve kış türleri arasında da yer almaktadır (Özhan. 2007). Rotiferlerin sucul sistemlerde şartların kötüleştiği dönemde fırsatçı türler olarak bilinmektedir (Gannon ve Stremberger. 1978). Kavşakkaya Baraj Gölü'de yaz mevsimindeki baskın türler Keratella cochlearis. Keratella tropica. Pompolyx sulcata ve Polyarthra dolichoptera. sonbahar mevsiminde Polyarthra dolichoptera. Synchaeta pectinata ve Cyclops sp. ve kış mevsimindeki en fazla populasyon yoğunluğuna sahip türler ise Cyclops sp.. Notholca squamula ve Synchaeta oblonga olarak bildirmişlerdir (Buyurgan. 2013). Tortum Gölü'nde yürütmüş olduğumuz araştırmamızda ise Asplanchna herricki ve Polyarthra sp. türlerine sadece kış aylarında rastlanılmıştır. Kopepod türleri ise benzer şekilde sonbahar ve kış aylarında baskın türler olmuşlardır.
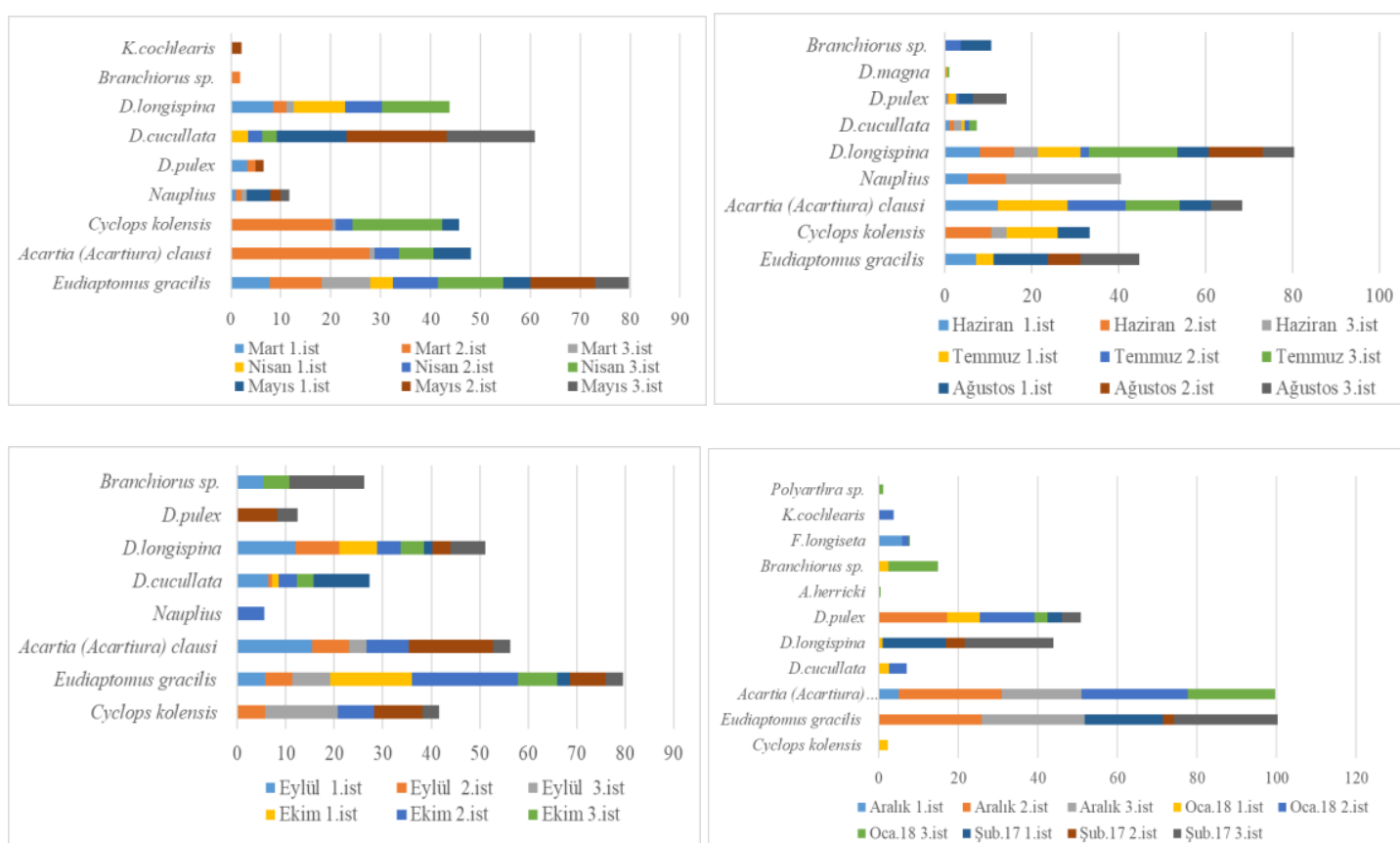

Şekil 3. Tortum Gölü zooplankton topluluklarının baskınlık değerlerinin aylara ve istasyonlara bağlı değişimi (\%)

$\mathrm{Bu}$ araştırmada zooplankton

topluluklarının Shannon-Wiener Çeşitlilik Indeksi değerlerinin istasyona bağı değişimi 3ist>2ist>1.ist şeklinde sıralanmıştır. Mevsime bağlı değişimi ise. Aralık en çeşitli (1.ist $0.17 \mathrm{H}^{\prime}$; 2. ist $0.26 \mathrm{H}^{\prime}$; 3 .ist $0.34 \mathrm{H}^{\prime}$ ) dönem. Şubat ise en az çeşitlilik $\left(0.01 \mathrm{H}^{\prime}\right)$ olduğu dönem olarak saptanmıştır (Şekil 4). Shannon-Wiener Çeşitlilik Indeksi değeri 1'in altında hesaplanmış ise ötrof seviyeyi. 3'ün üstünde hesaplanmış ise oligotrof seviyeyi gösterir (Öztürk. 2014). Bu bağlamda Tortum Gölü ötrofik ekolojik statüde yer almaktadır.

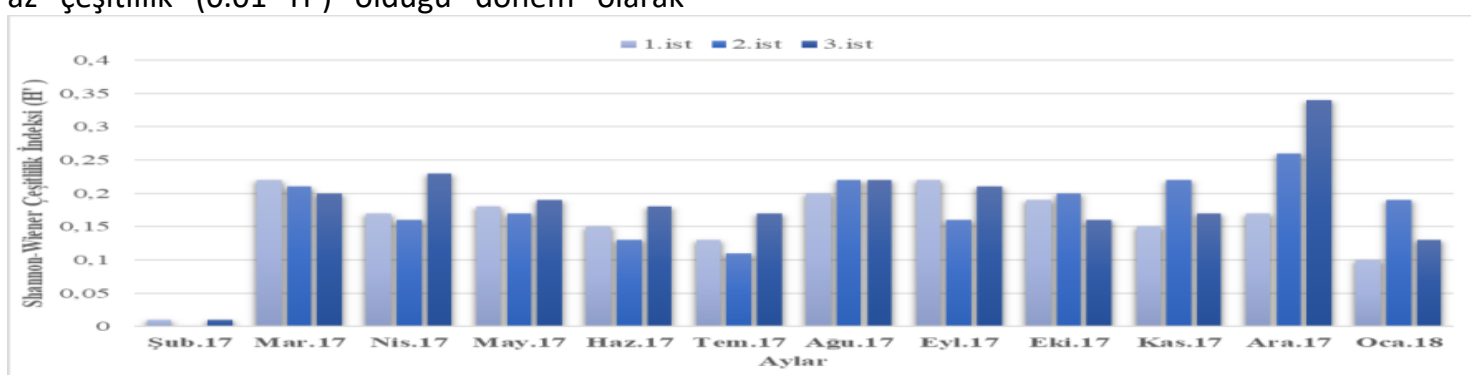

Şekil 4. Zooplankton toplulukları Shannon-Wiener Çeşitlilik İndeksi ( $\left.\mathrm{H}^{\prime}\right)^{\prime}$ nin aylara ve istasyonlara göre değişimi 
Zooplankton çeşitliliğini Margalef Çeşitlilik Indeksine göre. en yüksek çeşitlilik Ağustos 2. istasyonda (16.61 Dmg). en az çeşitlilik ise Şubat ayında bütün istasyonlarda tespit edilmiştir. Tüm aylarda istasyonlara bağlı çeşitlilik sıralaması 3.ist $>1$.ist $>2$.ist olarak saptanmıştır (Şekil 5). Keban Baraj Gölü. Hazar Gölü ve Dedeyolu Gölü'nde zooplanton topluluklarına göre Shannon-Wiener Çeşitlilik Indeksi değerleri sırasıyla $1.81 \mathrm{H}^{\prime}$. $1.47 \mathrm{H}^{\prime}$ ve
$1.51 \mathrm{H}^{\prime}$ olarak tespit etmişlerdir. Bununla birlikte bu üç gölde Margalef Çeşitlilik Indeksi uygulanmış ve sırasıyla $2.24 \mathrm{D}_{\mathrm{mg}}$. $2.26 \mathrm{D}_{\mathrm{mg}}$ ve $2.25 \mathrm{D}_{\mathrm{mg}}$ değerini saptamışlardır. Ayrıca bu göllerin çeşitliliğinin bahar aylarında en yüksek ve kış aylarında en düşük değerde olduğunu bildirmişlerdir (İpek. 2015). Tortum Gölü'nün Shannon-Wiener Çeşitlilik Indeksi ve Margalef Çeşitlilik Indeksi değerleri sırasıyla ortalama 0.17 $H^{\prime}$ ve $9.11 D_{m g}$ olarak hesaplanmıştır.

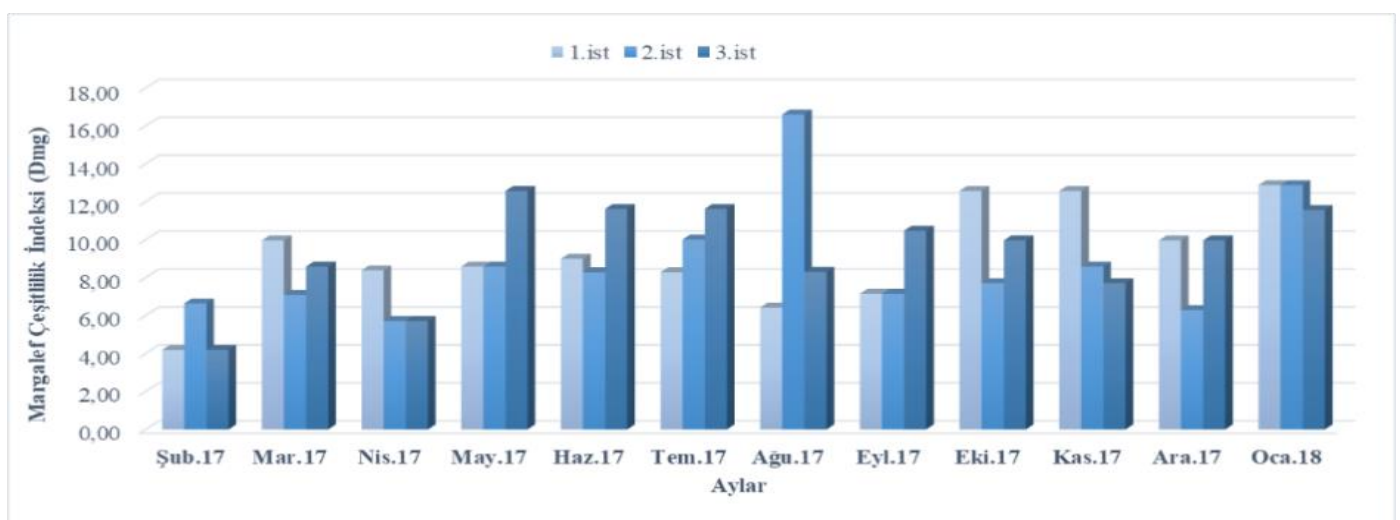

Şekil 5. Zooplankton toplulukları Margalef Çeşitlilik İndeksine ( $\left.D_{\mathrm{mg}}\right)^{\prime}$ nin aylara ve istasyonlara göre değişimi

\section{Sonuç ve Öneriler}

Sonuç olarak. Tortum Gölü gerek bazı su kalite parametreleri gerekse zooplankton topluluklarının mevsimsel değişimine göre ötrofikleşme sürecinde olan bir göl olarak değerlendirilebilir. Bu çalışma hem Tortum Gölü için hem de Erzurum îli için ilk olma özelliğine sahiptir. Tatlı su kaynaklarının öneminin arttığı günümüzde sucul ekosistemlere ait biyolojik çalışmaların yapılması mevcut su kaynaklarımızın şu anki durumu hakkında bilgi vermesinin yanı sıra geleceği hakkında yapılması planlanan çalışmalara ışık tutması açısından dikkate değer olduğu düşünülmektedir.

¥: Yüksek lisans tezinden üretilmiştir.

\section{Kaynaklar}

Akbay. N. 1982. Fitoplankton ve Zooplankton Hacim ve Ağırlıklarının (Biomass) Hesaplanmasında Geometrik Şekillerin Kullanılması. Bayındırlık ve İskan Bakanlığı DSi İşletme ve Bakım Dairesi Başkanlığı Keban. 30s.

Altındağ. A. ve Yiğit. S. 2004. Beyşehir Gölü Zooplankton Faunası ve Mevsimsel Değişimi. G.Ü Gazi Eğitim Fakültesi Dergisi . 24 (3). 217-225.
Altuner. Z. 1982. Tortum Gölü Fitoplankton ve Bentik Algleri Üzerinde Bir Araştırma. Atatürk Üniversitesi Fen Bilimleri Enstitüsü. Doktora Tezi (Basılmamış). 83s. Erzurum.

Anonim. 2012. Türkiye Çevre Mevzuatına göre kıta içi Su Kaynaklarının Sınıflarına Göre Su Kalite Kriterleri. Yüzeysel Su Kalitesi Yönetimi Yönetmeliği Birinci Bölüm. Orman ve Su İşleri Bakanlığı. Sayı: 28483 Resmi Gazete. 26s.

Buyurgan. Ö. 2013. Beş Farklı Tatlı Su Ekosisteminin (Doğal Göl. Baraj Gölü. Gölet. Akarsu. Havuz) Zooplankton Faunasının Mevsimsel Değişiminin Belirlenmesi ve Kanonik Uyum Analizi (Cca) Karşılaştırılması. Ankara Üniversitesi Fen Bilimleri Enstitüsü. Doktora Tezi. 135s. Ankara

Cirik S. ve Gökpınar Ş. 1999. Plankton Bilgisi ve Kültürü ders kitabı. Ege Üniversitesi Basım evi 2. Baskı. 274 s. İzmir.

Daday. E. 1903. Mikroskopiche Süsswassertiere aus Kleinasien. Sitzungsber. Akad. Wiss. Wien 112. Abt. 1: 139-167.

Dorak. Z.. Köker. L.. Gaygusuz. Ö.. Gürevin. C.. Akçaalan. R.. \& Albay. M. 2019. Zooplankton biodiversity in reservoirs of 
different geographical regions of Turkey: composition and distribution related with some environmental conditions. Aquatic Sciences and Engineering. 34(1). 29-38.

Duman. T.Y. 2009. The Largest Landslide Dam in Turkey: Tortum landslide. Engineering Geology. 104(1-2). 66-79.

Fakıoğlu. Ö.. Demir. Ş.M. ve Köktürk. M. 2014. Vertical Change of Same PhysicoChemical Parameters in Tortum Lake (Erzurum/Turkey). Jornal of Animal and Veterinary Advances. 13: 864-870.

Fakıoğlu. O.. Köktürk M.. A.S. Uzundumlu. H. Arslan. ve Atamanalp. M. 2018a. Planktonic-based assessment of the landside-dammed lake (ErzurumTurkey). Iranian Journal of Fisheries Sciences 17. no. 3: 503-515.

Fakıoğlu Ö.. Nuhoğlu A.. Acar. Ç. ve Eğercioğlu. M.N. 2018b. Derin Heyelan Set Gölü (Tortum Gölü)'nde Biyolojik ve Kimyasal Değişimlere Neden Olan Etkilerin Belirlenmesi. тÜBітAK 3001 projesi (116Y261). 67s.

Gannon. E. J. ve Stemberger. S.R. 1978. Zooplankton as indicators of water quailty. Trans Amer. Micros. Soc. Vol.97. No. 1. 67-35.

Güher. H. 2003. Mert.Erikli.Hamam ve Pedina(İğneada-Kırklareli) Göllerinin Zooplanktonik Organizmalarının Kommunite Yapısı. E.Ü Su Ürünleri Dergisi . 2 (1). 51-62.

İpek. N. 2015. Keban Baraj Gölü Yurtbaşı Mevkii Hazar Gölü ve Dedeyolu Göleti'nin zooplankton Faunası ve Mevsimsel Değişimlerinin Incelenmesi. Fırat Üniversitesi Fen Bilimleri Enstitüsü. Doktara Tezi s. 108

James. B.K. ve Adejare. L.I. 2010. Nutrients and Phytoplankton Production Dynamics of a Tropical Harbor in Relation to Water Quality Indices. Journal of American Science. 6(9): 261-275.

Kaya. M. ve Altındağ. A. 2007. Zooplankton Fauna and Seasonol Changes of Gelin Güllü Dam Lake (Yozgat-Türkey). Zooloji Türk Dergisi. 31 (4). 347-351.

Kivrak. E. 2006. Seasonal and Long Term Changes of The Phytoplankton in The Lake Tortum in Relation to Environmental Factors. Erzurum. Turkey. Biologia. 4: 339-345.
Kıvrak. E. ve Gürbüz. H. 2010. Tortum Çayı'nın (Erzurum) Epipelik Diyatomeleri ve Bazı Fiziko-Kimyasal Özellikleri ile illişkisi. Ekoloji. 19 (74):102-109

Kocataş. M. 2010. Ekoloji. Çevre Biyolojisi. Ege Üniversitesi Basımevi. ISBN: 978-975483-177-1. 597 s. İzmir.

Krebs. C.J. 1989. Ecological methodology (No. QH541. 15. S72. K74 1999.). New York: Harper and Row.765p.

Kwak. T. J. ve Peterson J.T. 2007. Community indices. parameters. and comparisons. Pages 677-763 in C.S. Guy and M.L. Brown. Editors. Analysis and interpretation of freshwater fisheries data. American Fisheries Society. Bethesda. Maryland. ISBN-13: 978-1888569-77-3.

Özdemir Mis. D.. Aygen. C.. Ustaoğlu. M.R. ve Balık. S. 2009. Tahtalı Baraj Gölü(Izmir)'nün Zooplankton Kompozisyonu. E.Ü Su Ürünleri Dergisi . 26 (2). 129-134.

Özhan. D. 2007. Karakaya Baraj Gölü Su Kalitesinin Zooplankton Kompozisyonu İle Değerlendirilmesi Nönü Üniversitesi Fen Bilimleri Enstitüsü. Yüksek Lisans Tezi. 98 s. Malatya

Öztürk. B.Y. 2014. “Apa Baraj Gölü Agleri Üzerine Araştırma (Çumra/Konya)". Selçuk Üniversitesi Fen Bilimleri Enstitüsü. Doktora Tezi. 236s.

Saler. S. 2004. Keban Baraj Gölü (Çemişgezek Bölgesi) Rotifera Faunasının Mevsimsel Değişim Gözlemleri. F.Ü Fen ve Mühendislik Bilimleri Dergisi . 16 (4). 695701.

Saler. S. ve Alış. N. 2014. Zooplankton Of Hancağız Dam Lake (Gaziantep-Turkey). Journal of Surver in Fisheries Sciences . 1 (1). 36-45.

Thorp. J.H. ve Covich. A.P. 2001. Ecology and classification of North American freshwater invertebrates. Academic press.1073p. USA.

Türkmen. M.. Naz. M. ve Dinler. Z. 2006. Gölbaşı Gölü'nün Zooplankton Tür Kompozisyonu ve Biyoması (Hatay-Türkiye). E.Ü Su Ürünleri Dergisi . 23 (1). 163- 167.

Ustaoğlu. M. R.. Balık. S.. Gezerler Şipal. U. ve Özdemir Mis. D. 2010. Buldan Baraj Gölü (Denizli) Planktonu ve Mevsimsel Değişimi. E.Ü Su Ürünleri Dergisi . 27 (3). 113-120. 
Ustaoğlu. M.R. 2015. An updated zooplankton biodiversity of Turkish inland waters. LimnoFish. 1(3). 151-159.

Velioğlu. A. ve Kırkağaç. M.V. 2017. Mogan Gölü Zooplankton'un Mevsimsel Değişimi.
Turkish Journal of Aquatic Sciences . 3 (32). 146-153. 